\title{
BMJ Open Exploring women's experiences of identifying, negotiating and managing perinatal anxiety: a qualitative study
}

\author{
Soo Oh, ${ }^{1}$ Carolyn A Chew-Graham, ${ }^{1,2}$ Victoria Silverwood, ${ }^{1}$ Sirah Aksa Shaheen, ${ }^{1}$ \\ Jacqualyn Walsh-House, ${ }^{1}$ Athula Sumathipala, ${ }^{1,2}$ Tom Kingstone (D) ${ }^{1,2}$
}

To cite: $0 \mathrm{~h} \mathrm{~S}$, Chew-

Graham CA, Silverwood V, et al. Exploring women's experiences of identifying, negotiating and managing perinatal anxiety: a qualitative study. BMJ Open 2020;10:e040731. doi:10.1136/ bmjopen-2020-040731

- Prepublication history additional material for this paper is available online. To view these files, please visit the journal online (http://dx.doi.org/10. 1136/bmjopen-2020-040731).

Received 22 May 2020 Revised 19 November 2020 Accepted 30 November 2020

Check for updates

(C) Author(s) (or their employer(s)) 2020. Re-use permitted under CC BY-NC. No commercial re-use. See rights and permissions. Published by BMJ.

${ }^{1}$ School of Medicine, Keele University, Keele, UK ${ }^{2}$ St George's Hospital, Midlands Partnership NHS Foundation Trust, Stafford, UK

Correspondence to Dr Tom Kingstone; t.kingstone@keele.ac.uk

\section{ABSTRACT}

Objectives Anxiety affects around $15 \%$ of women during the perinatal period and can adversely impact both mother and child, with potential implications for long-term health; few studies have examined women's experiences of perinatal anxiety (PNA). In the context of the National Institute for Health and Care Excellence prioritising PNA, this study aimed to explore women's experiences of the identification and management of PNA and their engagement with healthcare professionals.

Design Qualitative study with semi-structured interviews and applying thematic analysis.

Setting Recruitment materials were shared widely through maternal support groups, children's centres, libraries, National Health Service (NHS) providers (primary and secondary care) operating in the West Midlands or North West of England and through social media.

Participants Seventeen women (aged 25-42 years) with self-reported anxiety during pregnancy and/or up to 12 months postpartum. Interviews digitally recorded and transcribed with consent.

Results Three main themes and corresponding subthemes are described around a central concept of PNA as an individualised experience: barriers to disclosing PNA; help-seeking for PNA and establishing and engaging support networks. Disclosing, help-seeking and accessing systems of support were interconnected and contextualised by individualised experiences of PNA and pervaded by stigma.

Conclusions This research provides new insights into PNA and calls for awareness to be improved to achieve parity alongside depression and avoid missed opportunities in the provision of care for women and families. Future research should seek to develop novel PNA-specific interventions aimed at prevention, management and/or combatting stigma to support more women to disclose mental health concerns and seek help early.

\section{INTRODUCTION}

Perinatal anxiety (PNA) refers to anxiety that occurs during pregnancy and/or up to 12 months postpartum. ${ }^{1}$ PNA is reported to affect around $15 \%$ of women ${ }^{2}$ and is at least as common as depression across this period. $^{3}{ }^{4}$ PNA can be detrimental to the health and well-being of the (expectant) mother with increased risks of maternal

\section{Strengths and limitations of this study}

This study is the first, to our knowledge, to explore how women manage perinatal anxiety (PNA).

- A mixed recruitment strategy that included: primary and secondary care, community groups and social media.

- Analysis was conducted by a mixed team of researchers from different academic and clinical backgrounds.

- Generalisability may be limited by lack of diversity in some sample characteristics (ethnicity, sexuality and single mothers).

- Women experiencing acute distress may have been reluctant to self-identify.

depression and suicide reported..$^{5}$ Perinatal mental health problems, including anxiety, may also lead to adverse outcomes for infants with the following associations reported: impaired fetal development, preterm birth, increased risk of child maltreatment, bonding impairment, lower engagement with infant breast feeding and long-term cognitive, behavioural and emotional problems. ${ }^{5-11}$

Barriers to accessing appropriate care are reported at individual, service and system levels. The identification of a problem, influence of healthcare professionals particularly the lack of continuity of care, and stigma present key barriers to help-seeking for women experiencing perinatal psychological distress. ${ }^{11}$ A lack of standardised care of perinatal mental health $(\mathrm{PMH})$ problems across the UK has been reported; only $7 \%$ of women with PMH problems are referred to specialist care. ${ }^{12}$ A lack of awareness among healthcare professionals, difficulties distinguishing between 'normal' and clinical levels of anxiety and service fragmentation are also reported as barriers to the identification and management of PNA. ${ }^{13}$ The National Health Service (NHS) Mental Health Taskforce ${ }^{1415}$ recognise $\mathrm{PMH}$ services as a key priority and 
recommend an integrated physical-mental healthcare approach to support appropriate referrals, follow-up and management of women in community settings. ${ }^{16}$

To date, PNA has received significantly less attention in research than maternal depression. ${ }^{17}$ For example, a recent meta-synthesis of qualitative research on psychological distress, depression and anxiety during pregnancy ${ }^{18}$ included only one PNA-specific research paper (a rural study conducted in Cambodia). ${ }^{19}$ Women's accounts of PNA can be found in studies that take a dual focus on both anxiety and depression ${ }^{20-22}$; however, distinguishing the precise role of anxiety is complex. Only two qualitative studies have focused explicitly on PNA. ${ }^{23} 24$ Wardrop and Popadiuk ${ }^{23}$ explored transitions into motherhood with six postpartum women in Canada. Findings revealed a variety of PNA symptoms (physical and emotional), a sense of pressure felt by women to meet social expectations of motherhood and the invalidation of anxiety-related concerns by others, which prevented disclosure. Peer-support groups were recognised as essential resources, but exploration of these was limited. In a UK-based study, Hore et $a l^{24}$ examined women's $(\mathrm{n}=7)$ lived experiences of PNA; however, women with previous experience of miscarriage, traumatic births and/or in vitro fertilisation pregnancies were excluded, meaning important views may have been overlooked.

Set within a context where PNA has been identified as an NHS priority area, this research aimed to explore women's experiences of PNA focusing on previously underexamined aspects, including how women identify and manage symptoms (including self-management), engage with mental health services and use support networks.

\section{METHODS}

\section{Setting and participants}

Research ethics and Health Research Authority approvals were obtained for this study (see footnotes). Women over the age of 18 years, with capacity to consent and selfreported experiencing anxiety (described as: constant worrying, feeling unsettled) during pregnancy and/ or up to 12 months after birth were recruited. Women receiving inpatient treatment, experiencing an acute phase of anxiety or diagnosed with an ongoing severe mental illness-a psychological problem resulting in functional impairment, for example, schizophrenia or bipolar disorder-were excluded. Exclusion criteria were selected to ensure interviews focused on PNA (not another underlying mental illness) and did not interfere with specialist treatment. No upper limit was placed on 'time since' experience of PNA; where possible, women with recent experiences of PNA were interviewed to support data accuracy in terms of recall and relevancy to current clinical practice.

Posters and leaflets publicising the research were displayed in GP surgeries, community-based mental health services at a local NHS Trust, public libraries, children's centres and distributed among maternal support groups (eg, breast feeding and peer-support) operating in West Midlands and/or North West of England and via social media platforms (Twitter and Facebook). Potential participants were invited to contact the research team directly by email or telephone to express their interest in taking part. At which point, a comprehensive study information sheet was shared directing those interested to contact a member of the research team to schedule an interview.

\section{Data collection}

A qualitative methodology was applied in this research to suit the exploratory nature of the research aims and objectives. $^{25}$ One-to-one semi-structured interviews supported exploration of this potentially sensitive topic. Interviews were conducted by experienced qualitative researchers (TK and VS). TK has a background in social science, and VS is an academic General Practitioner (GP); both conducted data collection on a recent PNA study involving Healthcare Professionals (HCPs).$^{13}$ Interviews were conducted face to face or by telephone and took place at the participant's home, Keele University or Midlands Partnership NHS Foundation Trust. Interview formats and locations were selected based on participant preferences.

The topic guide (online supplemental document 1) was informed by a patient advisory group and covered demographic characteristics (to support description of the sample), experiences of anxiety across the perinatal period, management strategies, social support, past experience of mental health problems and interactions with healthcare providers. The research team met regularly to review and adapt the topic guide in response to concurrent data analysis.

At the end of interviews, the interviewer informed the participant about the next steps, how their data would be used and checked on their well-being prior to leaving the interview setting. A risk protocol was used to ensure appropriate support was provided to participants in the event of the disclosure of suicide ideation.

\section{Analysis}

Interviews were audio-recorded with consent and transcribed verbatim by an external transcription service or member of the research team. Data analysis followed an inductive and interpretive thematic approach ${ }^{26}$ applying principles of constant comparison to analyse differences across cases. ${ }^{27}$ The lead author (SO) - Academic Foundation Trainee and Foundation Year 2 doctor in obstetrics and gynaecology-coded all transcripts, drawing on wider clinical experiences, to inform interpretations of the data and identify themes of interest and apparent importance. The research team, representing a mix of different professional backgrounds, coded a subset of transcripts and worked collaboratively to discuss supporting and competing interpretations of the data before agreeing on the key themes. ${ }^{28}$ Analysis and data collection occurred iteratively guided by inductive thematic saturation ${ }^{29}$; data 
Table 1 Participant characteristics

\begin{tabular}{|c|c|c|}
\hline Participant ID & $\begin{array}{l}\text { Number of } \\
\text { children (age of } \\
\text { youngest child) }\end{array}$ & $\begin{array}{l}\text { First anxiety episode } \\
\text { occurred }\end{array}$ \\
\hline W001 & $\begin{array}{l}1 \text { (1 year, } 5 \\
\text { months) }\end{array}$ & $\begin{array}{l}\text { Prepregnancy ( } 12 \\
\text { months prior to } \\
\text { pregnancy) }\end{array}$ \\
\hline W002 & 1 (3 months) & During adolescence \\
\hline W003 & $\begin{array}{l}2 \text { (1 year, } 11 \\
\text { months) }\end{array}$ & $\begin{array}{l}\text { Postnatal stage (second } \\
\text { child) }\end{array}$ \\
\hline W004 & 3 (6 months) & $\begin{array}{l}\text { Antenatal stage } \\
\text { (second child) }\end{array}$ \\
\hline W005 & $\begin{array}{l}1 \text { (1 year, } 8 \\
\text { months) }\end{array}$ & Postnatal stage \\
\hline W006 & 3 (3 months) & During adolescence \\
\hline W007 & 1 (12 year) & Antenatal stage \\
\hline W008 & 2 (6 months) & During adolescence \\
\hline W009 & $\begin{array}{l}1 \text { (1 year, } 6 \\
\text { months) }\end{array}$ & Antenatal stage \\
\hline W010 & 2 (9 months) & Postnatal stage \\
\hline W011 & $0^{*}$ & $\begin{array}{l}\text { Prepregnancy ( } 24 \\
\text { months prior to } \\
\text { pregnancy) }\end{array}$ \\
\hline W012 & 3 (2 months) & $\begin{array}{l}\text { During labour (second } \\
\text { child) }\end{array}$ \\
\hline W013 & $\begin{array}{l}2 \text { (1 year, } 6 \\
\text { months) }\end{array}$ & $\begin{array}{l}\text { Postnatal stage (second } \\
\text { child) }\end{array}$ \\
\hline W014 & 2 (2 months) & During adolescence \\
\hline W015 & 5 (3 months) & $\begin{array}{l}\text { First pregnancy ( } 8 \text { years } \\
\text { ago) }\end{array}$ \\
\hline W016 & $\begin{array}{l}1 \text { (1 year } 2 \\
\text { months) }\end{array}$ & Antenatal stage \\
\hline W017 & 1 (1 year) & $\begin{array}{l}\text { Prepregnancy ( } 24 \\
\text { months prior to } \\
\text { pregnancy) }\end{array}$ \\
\hline
\end{tabular}

${ }^{\star}$ Expecting first child at time of interview.

collection ceased when no new codes or themes were identified.

\section{Patient and public involvement}

Members of a maternal mental health patient advisory group contributed to the conceptualisation of the study, drafting of participant-facing study documents, design of recruitment strategies, development of the topic guide and reviewed preliminary analysis.

\section{RESULTS}

Seventeen women were interviewed: mean age $=33$ years (range $=25-42$ years); the majority $(16 / 17)$ were living with a partner and employed (15/17) in either full-time or part-time roles $(7 / 15$ were currently taking maternity leave). Table 1 provides information relating to number of children and first episode of anxiety. Average interview length was $70 \mathrm{~min}$ (range=39-95 $\mathrm{min}$ ). The majority of interviews $(14 / 17)$ were conducted face to face; all but two of which took place in the participant's home.

\section{Analytic themes}

For the purpose of this paper, three main themes and corresponding subthemes are presented: (1) barriers to disclosing PNA, (2) help-seeking for PNA and (3) establishing and engaging support networks. Table 2 provides an overview of the themes and subthemes. Themes presented in this paper have been selected to inform healthcare service recommendations; additional themes were generated but are not described. Themes are organised around a central concept of PNA as an individualised experience. Highly individualised experiences of PNA were set within complex biographical, temporal, familial and social contexts and represented focal points informing decision making in relation to the other themes. Individuals described past experiences of mental health problems, prior miscarriage leading to increased apprehension and alertness, challenges conceiving a child, problems during pregnancy regarding the health of the baby, traumatic birth experiences and stresses and strains relating to childcare. Selected narrative data are presented in box 1 to provide contextual information.

\section{Barriers to disclosing PNA}

Factors preventing the disclosure of mental health concerns to others included: stigma (with internal and external sources reported) and missed opportunities. These factors delayed help-seeking and access to (in) formal support.

\section{Stigma}

Women were reluctant to openly discuss their mental health concerns with HCPs for fear of being judged; shame and embarrassment led women to disguise their concerns:

Table 2 Table of main and subthemes

\section{Organising concept PNA as an individualised experience}

\begin{tabular}{llll}
\hline Theme & Barriers to disclosing PNA & Help-seeking for PNA & $\begin{array}{l}\text { Establishing and engaging support } \\
\text { networks }\end{array}$ \\
\hline Subtheme & $>$ Stigma & $>$ Recognising anxiety & $>$ Family \\
& $>$ Missed opportunities & $>$ Managing anxiety & $>$ Friends and peer support group \\
& & & Healthcare Professionals \\
\hline
\end{tabular}


Box 1 Examples of individualised accounts of perinatal anxiety (PNA)

History of mental health problems

- 'I've had three children and anxiety has always been present for part of my life and I kind of accepted that, I'm always going to have it, it's part of my genetic makeup, it was how I managed it, etc, and medication helped me throughout all three pregnancies'. (W006)

\section{Experience of miscarriage}

- 'It was the loss of the first baby the anxiety kicked in. And then obviously having a second miscarriage, I had that three months after my first miscarriage and then it took us nine months to get pregnant again. And I think as soon as I was pregnant again with my son I was on high alert basically from the word go'. (W018)

\section{Childcare responsibilities}

- 'When I had my second [child] I thought l'd prepared myself. I knew it was going to be more difficult for two but I don't think l'd quite prepared myself as much... it was having to be back for the school run because me eldest had started reception, so he'd started school only three or four months before I had the youngest. So it's kind of like learning how short the day is and how you've got to be back for half-past three, so it was kind of like clock-watching and then really getting panicky'. (W003)

"[I told] few of my close friends, but no, not really because you sort of hide it, don't you? You're just, like, embarrassed." (W009)

Women described having their concerns dismissed by others; this prevented full disclosure:

"You daren't say when you're shot down the moment you speak up. You can't then go on to how bad you're feeling $[\ldots]$ because people say, 'Oh no, no, it's the norm. It's the norm.' And they just shoot you down."

(W008)

Women described internalised views of motherhood informed by representations in traditional media and images of other mothers on social media. Failure to meet these expectations contributed to feelings of anxiety and stigma that prevented disclosure:

"I kind of had an idea about what motherhood would be like and what I would be like and I kind of thought to myself, I'm going to be this, I'm going to be strong. And I wasn't. And I found myself to be quite paranoid, very panicky, and then I think at the same time feeling an element of disappointment in myself that I wasn't better. And feeling very lonely, and just feeling like a fish out of water to be honest." (W005)

Women were sensitive to stigma related to anxiety and perceived maternal depression as more acceptable; concerns about PNA were commonly minimised by others:

"It's still a bit of a dirty word, 'anxiety'. Depression seems like, 'Oh well that's okay, because that's quite serious' but anxiety I think there is still, 'Oh my goodness girl, pull yourself together, crack on!" (W008)

\section{Missed opportunities}

Some women described having positive relationships with HCPs (GPs, midwives and health visitors), which supported them to disclose mental health concerns. However, a lack of appropriate follow-up meant important opportunities to support disclosure and help-seeking were missed:

"[At the booking appointment] I had an absolute breakdown again and it really knocked me, I felt terrible, I was anxious, you don't know if you're going to carry the child, so some of the questions that she [the midwife] was asking me and I can't remember the name of the questions, it's just like a brief three or four questions about if you've had, not suicidal thoughts, if you've had like maybe low thoughts and you've felt like it would be better off if you weren't here, those kind of questions. And I answered yes to two of them and she looked at me and went, 'really?' and she just instantly broke any kind of rapport." (W011)

Such missed opportunities devalued women's experiences of PNA and had implications in terms of access to appropriate support services.

\section{Help-seeking for PNA}

Accounts of help-seeking suggest decisions to seek external support were initiated when women came to the realisation that anxiety was impacting their day-to-day life, childcare responsibilities or where physical symptoms presented.

\section{Recognising anxiety}

Women described noticing changes in themselves; changes that manifested in different ways through physical and/or psychological presentations of anxiety:

"I wouldn't take him [baby] out; I didn't want to see anyone. Just crying for no reason or being really frustrated at my baby. To the point where I was, like, thinking I was going to faint, like, I got like palpitations and like, when you're dizzy. I think that was the point where I realised, perhaps it was, perhaps I do need help, can't do it, like, on your own." (W009)

Some women also identified how changes in the way they were feeling and acting potentially put their own child/children at risk; this recognition prompted some to take action:

"So I went from that [being confident] to not being that person really anymore and I was so, I was just incredibly sort of paranoid and anxious, and I mean I was always worried that something would happen to him [baby]." (W002) 


\section{Trying to manage}

Recognition of anxiety and the level of disclosure (how much and to whom) affected how women managed their PNA. Women described various strategies to manage their symptoms including: exercise, relaxation and mindfulness techniques, digital technology, peer support groups and psychological therapies.

Exercise during pregnancy also provided an opportunity to support mental health and well-being:

"I went to something called aquanatal, which is antenatal swimming, aerobic type things so like those networks but that wasn't necessarily mental health but it was with people. So you could talk about how's your pregnancy going and that type of thing [...] But you have to go and source that yourself if you know what I mean, rather than your midwife telling you." (W001)

After birth, constraints on time and childcare responsibilities posed potential barriers to exercise; activities that included baby were therefore helpful:

"And my last two pregnancies definitely trying to do exercise but I just haven't had the time to fit that in this time so I have tried to do a bit of buggy fit. So I think those sort of things definitely do help and getting outside." (W014)

Relaxation techniques were described; this participant reflects on how she would use mindfulness techniques to contain rising anxiety:

"So if I was waking in the night or if I'd had any kind of flashbacks and things and bringing myself back to kind of the now and the present so doing the whole name five things you can see in the room, five things you can hear, what can you smell to bring yourself back to the present. So I know that I've used that quite a bit." (W014)

Digital technology was used by some women to monitor the safety of their child, which helped reduce their anxiety:

"Yeah, just having that technology [Angel Sensor $\mathrm{Pad}$ ] because obviously the alarm would go off and I mean don't get me wrong, I still woke up in the middle of the night to check he [baby] was breathing but as soon as I saw like that he was breathing and I saw that the monitor was working, like with the, they have like a little pendulum thing, I said, okay its working, he's fine, it's okay." (W005)

Women also described using mobile phone apps to support guided self-help. These apps also facilitated communication between women and their peer support group(s), as this participant described in relation to a breastfeeding group:

"It's parent led so it's just mums supporting each other which I think is nice actually and we've got a Whatsapp group so if you are struggling you know like and you've got another five days or whatever until the group, you can put something on there and you know that they'll all help you with loads of advice and whatever." (W002)

Some women described accessing psychological therapies including cognitive-behavioural therapy (CBT) and counselling. Talking therapies were helpful in providing a safe space for discussion:

"I felt that I didn't really have anyone to talk to outside of my husband's family and you've got to be careful when it's your husband's family. I kind of wanted someone who was my own to talk to." (W003)

\section{Establishing and engaging support networks}

Social networks provided important practical, social and emotional support for women experiencing PNA. The composition of these networks differed depending on access but commonly included partners, immediate and extended family, existing friends, members of peer support groups and HCPs.

\section{Family}

In most cases, the husband or partner played a central role in participant's support networks (although only one single parent was interviewed):

"I probably only talk to him [partner] about it. But I am fortunate that I've got him, because I don't quite know, if you didn't have a supportive partner... yeah, I'm not quite sure, you'd probably go mad! because even your close family and stuff you don't necessarily see that much." (W008)

However, husbands or partners may not necessarily provide the most appropriate support, especially where they have their own mental health problems, or particular views on mental health:

"He understands anything to do with physical illness, anything mental-wise he just doesn't get and that's difficult if the support network- because you have support from friends and you have support from other women who go through it but the person at home doesn't get it and, cause he's just not that way inclined to get it so, that made things difficult definitely." (W005)

The support provided by immediate family members varied and, in some cases, even added to existing stress:

"I think the worst one really is like some immediate family members, which you kind of expect would be non-judgmental and most understanding but in my situation they are the worst ones, you know." (W006)

\section{Friends and peer support group members}

The role of existing friends in women's networks varied depending on whether they themselves had children and could empathise through shared experiences: 
"My friends who did have babies, I was able to be really honest with them and sort of talked to them about how I was struggling. And again they did a lot of normalising [...] I remember my best friend, she's got a little boy and he's three now, she's just had her second actually, but text her something: 'I feel awful', she was like, 'What? Do you mean you don't enjoy not freezing day after day and putting them to bed and feeding them all of the time?' you know, as a joke sort of thing, she's like, it's not fun, it's really not fun at times and that's a normal way to feel." (W010)

The majority of participants were members of local support groups; often these groups targeted new mums and/or breast feeding. These groups facilitated openness and honesty among members:

"I think as a group I think the group is quite unusual but I think everyone just knitted together really, really well and you could say anything and you knew you wouldn't be judged." (W017)

However, peer support groups were not accessible for all women; barriers to engagement were described including lack of local provision, discontinuation of groups and anxiety about group settings:

"It's just hard going to like baby groups. I've got a list of things I'm to do but you know it's actually achieving them. Like just going baby groups, I want to do this and take her on like little trips out with my other two boys and things, you know, but I know I stop myself mentally from doing it because I exhaust myself mentally that much that I just don't get out to do it." (W006)

\section{Healthcare Professionals (HCPs)}

Women described positive and negative experiences of their encounters with HCPs. Key factors that supported positive relationships were described, including compassion, empathy and giving time to explore concerns (on a broad range of topics):

"Most moms do find themselves co-sleeping, so she [Health Visitor] told us how to safely do it which I thought, you know, that's so much better than saying 'don't do it', and you go and do it, you know, that's how accidents happen. So she was ace and I've been back and I've seen them quite a few times with questions that I've had." (W002)

"She [The GP] was really understanding [...] asked me lots of questions about what I was feeling. She also signposted me to lots of groups as well." (W001)

Lack of continuity in care limited the extent to which relationships between women and their HCPs could be nurtured:

"I didn't want help from someone I didn't know, like I didn't know my Health Visitor, I didn't know my Midwife, cause that's the thing with like, it's just the

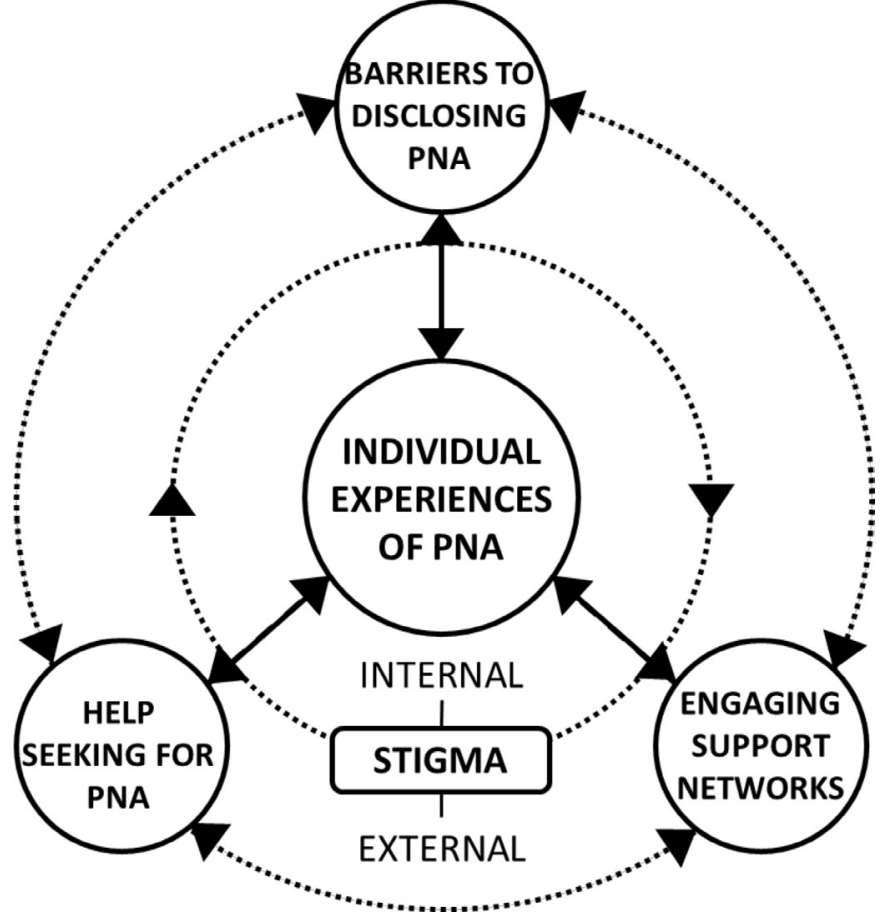

Figure 1 Diagram of relationship between themes and organising concept. PNA, perinatal anxiety.

way with the NHS now, you don't know the person that's taking care of you, you don't build a relationship with them, so why am I going to talk to that person?" (W005)

\section{DISCUSSION}

This research revealed how issues of disclosure, helpseeking and access to systems of support interconnected and were contextualised by individualised experiences of PNA pervaded by internal (personal sense of shame and devaluation) and external (sense of discrimination) forms of stigma (as presented in figure 1). Maternal mental health remains a sensitive and stigmatised subject for women; participants described anxiety as a 'dirty word', and their accounts revealed greater levels of acceptance towards maternal depression among peers and HCPs. Social networks played a crucial support role for many, although network composition varied depending on access to individuals and groups, provision of services, relationships with HCPs and social confidence.

Previous research has highlighted how frustration contributes to PNA and is associated with managing the unfamiliarity, uncertainty and uncontrollability of pregnancy ${ }^{24}$ and adjustment across the perinatal period. ${ }^{22}$ Participants in our research revealed how biographical factors such as personal and familial-related histories of mental health and pregnancy-related complications and incidents informed presentations of PNA; such experiences were discounted in previous research. ${ }^{24}$

PNA related to social expectations of motherhood and mental health stigma have been reported ${ }^{1821-24}$ and tend 
to converge around fears of being perceived as a 'bad mother' ${ }^{30}$ Maintaining the identity as a 'good mother' is a social imperative; however, in the context of maternal mental health problems, women tread a discursive and precarious line between control and conflict, being responsible and being dangerous. ${ }^{18} 31$ Participants in our research described withholding disclosure of PNA to maintain a sense of control and preserve characteristics of their self-concept, which fit idealised representations of motherhood. Avoidance of being labelled with a mental health problem therefore prevented women from accessing mental healthcare services. ${ }^{32}$ Notions of 'double stigma' also seem apparent and relevant; women described feeling stigmatised due to their mental health problem and as a mother with a mental health problem. ${ }^{33}$ As women sought to distance themselves from labels of anxiety, they seemingly failed to identify themselves as legitimate candidates for care. ${ }^{34}$ Interestingly, participants in our research perceived depression as a more accepted and legitimate condition, which has not been reported before.

Service-level barriers to disclosure identified elsewhere, such as a lack of time and continuity of care, ${ }^{11212235}$ were evidenced in the present study. Our research highlighted missed opportunities in healthcare encounters to support disclosure and help-seeking for PNA; by not responding to mental health cues of women, HCPs could not provide appropriate signposting and jeopardised their relationships with patients. Missed opportunities are likely to be common in the context of the fragmentation of perinatal care reported by HCPs. ${ }^{13}$ An apparent clinical preoccupation with depression also invalidated women's experiences and concerns about PNA. ${ }^{23}$

Our research provides new insights into experiences of managing PNA. Exercise (preferably activities that involved their child), mindfulness techniques, digital technologies and psychological therapies were described by women in this study. Evidence for these strategies appears mixed. Systematic review findings report the effectiveness of mindfulness-based interventions for PNA and depression, ${ }^{36}$ prenatal exercise for depression but not anxiety, ${ }^{37}$ but evidence for CBT remains scant and heterogeneous. ${ }^{38} \mathrm{~A}$ gap in mobile phone-based interventions targeting PNA prevention, screening and/or management also seems apparent. ${ }^{39}$ Our study did highlight the role and function of support networks and identified key members, including: family, existing friends, peer support group members and/or HCPs. Women in our study tended to gravitate towards members of their social network who could offer empathy based on shared experiences, which echoes the 'leaning towards peer-support' described by Walker $e t a t^{40}$ in the context of people experiencing mental health crises. Peer-led and/or designed interventions could offer a valuable resource.

\section{Strengths and limitations}

This research provides new insights into the identification and management of PNA specifically in relation to disclosure, help-seeking and the role of systems of support. The mixed recruitment strategy was effective in supporting the gathering of a broad range of PNA experiences. The decision to include participants that self-identified PNA (but not necessarily diagnosed) was informed by the literature on help-seeking for maternal mental health problems. Analysis was rigorous, ceasing once inductive thematic saturation had been achieved, and was supported by robust collaboration and debate within the mixed team of researchers. ${ }^{28}$

This research has some limitations. The lack of diversity of the sample according to certain characteristics (ethnicity, sexuality and single mothers) may mean important experiences and perspectives are missing. Women experiencing acute distress may also have been reluctant to self-identify. The majority of participants were also members of local support groups and therefore linked into systems of support.

\section{Implications for research and practice}

In clinical practice, greater emphasis should be placed on building relationships between women and HCPs to support disclosure, help-seeking and avoid potential missed opportunities to identify PNA. Taking a more in-depth approach to history taking may be warranted to support the identification of risk factors for PNA. Taking opportunities to enquire about women's access to social and peer support should also be considered. While improvements in the recognition and management of maternal depression have been made and should continue, parity is now needed for anxiety. Future research should consider the views of unheard groups (eg, single mothers, ethnic minorities and same-sex couples) and synthesise qualitative findings to inform development of novel PNA-specific interventions aimed at prevention, management, combatting stigma and support early detection and signposting.

Contributors CC-G, TK, AS and VS designed and conceptualised the research study. TK and VS collected all data. All authors reviewed transcripts and contributed interpretations to the analysis process. SO led manuscript writing with contributions from TK and CC-G. All authors reviewed the manuscript.

Funding This work was supported by Midlands Partnership NHS Foundation Trust who provided funding to cover project costs. During completion of the research, SAS was funded by an ASPIRE studentship from their Medical School, and VS was funded by a National Institute for Health Research (NIHR) Academic Clinical Fellowship. CC-G is partially funded by NIHR West Midlands Applied Research Collaboration.

Competing interests None declared.

Patient consent for publication Not required.

Ethics approval Research ethics approval was obtained in July 2018 from the Faculty of Medicine and Health Sciences Research Ethics Committee, Keele University (Reference: 18/L0/1233). HRA approval was obtained to conduct this research at Midlands Partnership NHS Foundation Trust (MPFT).

Provenance and peer review Not commissioned; externally peer reviewed.

Data availability statement Data are available on reasonable request.

Supplemental material This content has been supplied by the author(s). It has not been vetted by BMJ Publishing Group Limited (BMJ) and may not have been peer-reviewed. Any opinions or recommendations discussed are solely those of the author(s) and are not endorsed by BMJ. BMJ disclaims all liability and 
responsibility arising from any reliance placed on the content. Where the content includes any translated material, BMJ does not warrant the accuracy and reliability of the translations (including but not limited to local regulations, clinical guidelines, terminology, drug names and drug dosages), and is not responsible for any error and/or omissions arising from translation and adaptation or otherwise.

Open access This is an open access article distributed in accordance with the Creative Commons Attribution Non Commercial (CC BY-NC 4.0) license, which permits others to distribute, remix, adapt, build upon this work non-commercially, and license their derivative works on different terms, provided the original work is properly cited, appropriate credit is given, any changes made indicated, and the use is non-commercial. See: http://creativecommons.org/licenses/by-nc/4.0/.

\section{ORCID iD}

Tom Kingstone http://orcid.org/0000-0001-9179-2303

\section{REFERENCES}

1 National Institute for Health and Care Excellence (NICE). Antenatal and postnatal mental health: clinical management and service guidance CG192, 2014. Available: https://www.nice.org.uk/guidance/ cg192 [Accessed 01 May 2020].

2 Fairbrother N, Janssen P, Antony MM, et al. Perinatal anxiety disorder prevalence and incidence. J Affect Disord 2016;200:148-55.

3 Biaggi A, Conroy S, Pawlby S, et al. Identifying the women at risk of antenatal anxiety and depression: a systematic review. J Affect Disord 2016;191:62-77.

4 Giardinelli L, Innocenti A, Benni L, et al. Depression and anxiety in perinatal period: prevalence and risk factors in an Italian sample. Arch Womens Ment Health 2012;15:21-30.

5 Alder J, Fink N, Bitzer J, et al. Depression and anxiety during pregnancy: a risk factor for obstetric, fetal and neonatal outcome? A critical review of the literature. J Matern Fetal Neonatal Med 2007;20:189-209.

6 Talge NM, Neal C, Glover V, et al. Antenatal maternal stress and long-term effects on child neurodevelopment: how and why? J Child Psychol Psychiatry 2007;48:245-61.

7 Loomans EM, van der Stelt O, van Eijsden M, et al. High levels of antenatal maternal anxiety are associated with altered cognitive control in five-year-old children. Dev Psychobiol 2012;54:441-50.

8 Staneva A, Bogossian F, Pritchard M, et al. The effects of maternal depression, anxiety, and perceived stress during pregnancy on preterm birth: a systematic review. Women Birth 2015;28:179-93.

9 Nath S, Pearson RM, Moran P, et al. The association between prenatal maternal anxiety disorders and postpartum perceived and observed mother-infant relationship quality. J Anxiety Disord 2019;68:102148.

10 Fallon V, Groves R, Halford JCG, et al. Postpartum anxiety and infant-feeding outcomes. J Hum Lact 2016;32:740-58.

11 Button S, Thornton A, Lee S, et al. Seeking help for perinatal psychological distress: a meta-synthesis of women's experiences. $\mathrm{Br}$ $J$ Gen Pract 2017;67:e692-9.

12 Royal College of Obstetricians \& Gynaecologists. Maternal mental health - women's voices, 2017. Available: https://www.rcog.org.uk/ en/patients/maternal-mental-health---womens-voices/ [Accessed 01 May 2020].

13 Silverwood V, Nash A, Chew-Graham CA, et al. Healthcare professionals' perspectives on identifying and managing perinatal anxiety: a qualitative study. Br J Gen Pract 2019;69:e768-76.

14 NHS Mental Health Task Force. Five year forward view for mental health, 2016. Available: https://www.england.nhs.uk/wp-content/ uploads/2016/02/Mental-Health-Taskforce-FYFV-final.pdf [Accessed 01 May 2020].

15 NHS Mental Health Task Force. Five year forward view for mental health: one year on, 2017. Available: https://www.england.nhs.uk/ publication/five-year-forward-view-for-mental-health-one-year-onreport/ [Accessed 01 May 2020].
16 Department for Health. Closing the gap: priorities for mental health, 2014. Available: https://www.gov.uk/government/publications/ mental-health-priorities-for-change

17 Brockington I, Butterworth R, Glangeaud-Freudenthal N. An international position paper on mother-infant (perinatal) mental health, with guidelines for clinical practice. Arch Womens Ment Health 2017;20:113-20.

18 Staneva AA, Bogossian F, Wittkowski A. The experience of psychological distress, depression, and anxiety during pregnancy: a meta-synthesis of qualitative research. Midwifery 2015;31:563-73.

19 MacLellan J. Antenatal anxiety in pregnant women from rural Cambodia. Br J Midwifery 2010;18:735-43.

20 Bennett HA, Boon HS, Romans SE, et al. Becoming the best mom that I can: women's experiences of managing depression during pregnancy--a qualitative study. BMC Womens Health 2007;7:13.

21 Highet N, Stevenson AL, Purtell C, et al. Qualitative insights into women's personal experiences of perinatal depression and anxiety. Women Birth 2014;27:179-84.

22 Nagle U, Farrelly M. Women's views and experiences of having their mental health needs considered in the perinatal period. Midwifery 2018;66:79-87.

23 Wardrop AA, Popadiuk NE. Women's Experiences with Postpartum Anxiety: Expectations, Relationships, and Sociocultural Influences. Qual Rep 2013;18:6.

24 Hore B, Smith DM, Wittkowski A. Women's experiences of anxiety during pregnancy: An interpretative phenomenological analysis. $J$ Psychiatry Behav Sci 2019;14:15.

$25 \mathrm{Sim}$ J, Wright C. Research in health care: concepts, designs and methods. Nelson Thornes, 2000.

26 Clarke V, Braun V, Hayfield N. Thematic analysis. In: Smith JA, ed. Qualitative psychology: a practical guide to research methods. 3rd edition. Sage Publications, 2015.

27 Fram S. The constant comparative analysis method outside of Grounded theory. Qual Rep 2013;18:1-25.

28 Fernald DH, Duclos CW. Enhance your team-based qualitative research. Ann Fam Med 2005;3:360-4.

29 Saunders B, Sim J, Kingstone T, et al. Saturation in qualitative research: exploring its conceptualization and operationalization. Qual Quant 2018;52:1893-907 https://doi.org/

30 Kingston DE, Biringer A, Toosi A, et al. Disclosure during prenatal mental health screening. J Affect Disord 2015;186:90-4.

31 Staneva AA, Wigginton B. The Happiness imperative: exploring how women narrate depression and anxiety during pregnancy. Fem Psychol 2018;28:173-93.

32 Corrigan P. How stigma interferes with mental health care. Am Psychol 2004;59:614-25.

33 McLoughlin J. Stigma associated with postnatal depression: a literature review. Br J Midwifery 2013;21:784-91.

34 Dixon-Woods M, Cavers D, Agarwal S, et al. Conducting a critical interpretive synthesis of the literature on access to healthcare by vulnerable groups. BMC Med Res Methodol 2006;6:35.

35 Chew-Graham CA, Sharp D, Chamberlain E, et al. Disclosure of symptoms of postnatal depression, the perspectives of health professionals and women: a qualitative study. BMC Fam Pract 2009;10:7.

36 Shi Z, MacBeth A. The effectiveness of mindfulness-based interventions on maternal perinatal mental health outcomes: a systematic review. Mindfulness 2017;8:823-47.

37 Davenport MH, McCurdy AP, Mottola MF, et al. Impact of prenatal exercise on both prenatal and postnatal anxiety and depressive symptoms: a systematic review and meta-analysis. $\mathrm{Br} J$ Sports Med 2018;52:1376-85.

38 Marchesi C, Ossola P, Amerio A, et al. Clinical management of perinatal anxiety disorders: a systematic review. J Affect Disord 2016;190:543-50.

39 Hussain-Shamsy N, Shah A, Vigod SN, et al. Mobile health for perinatal depression and anxiety: Scoping review. J Med Internet Res 2020;22:e17011.

40 Walker S, Kennedy A, Vassilev I, et al. How do people with longterm mental health problems negotiate relationships with network members at times of crisis? Health Expect 2018;21:336-46. 